\title{
Estética e Educação Ambiental no paradigma da complexidade
}

\author{
Claudia Moraes Silveira Tavares ${ }^{1}$ \\ Claudia Mariza Mattos Brandão ${ }^{2}$ \\ Elisabeth Brandão Schmidt ${ }^{3}$
}

Resumo: $O$ artigo objetiva apresentar algumas aproximações entre Estética, Educação Ambiental (EA) e a Epistemologia da Complexidade de Edgar Morin, visando a contribuir para o entendimento da situação socioambiental vigente, na consideração de que as transformações dos valores éticos e estéticos modificam atitudes e comportamentos nas relações dos sujeitos com 0 meio ambiente. A Educação Ambiental, mais do que uma nova forma de pensar ou agir, representa a possibilidade de (res)significação e renovação do próprio pensamento/ conhecimento humano. Nesse contexto, a Estética apresenta-se como elemento fundamental que viabiliza a compreensão sensível dos fatores culturais e sociais, possibilitando o surgimento de diferentes mentalidades e comportamentos. Tal abordagem propicia problematizarmos a questão a partir de sutis deslocamentos, como o poder poético e político de elementos institucionalizados, refletindo sobre as relações entre ética e estética, política e arte, na sociedade contemporânea.

Palavras-chave: Estética; Educação Ambiental; Complexidade.

Abstract: This article aims to present some approaches between Aesthetics, Environmental Education (EE) and Edgar Morin's epistemology of complexity, willing to contribute to the understanding of the present socioenvironmental situation, considering that transformations of ethical and aesthetics values modify attitudes and behaviours in the relations between humans and environment. Environmental Education, more than a new way of

1 Graduada em Artes Visuais - Licenciatura Plena/FURG; Mestre em Educação Ambiental e pesquisadora do PhotoG raphein - Núcleo de Pesquisa em Fotografia e Educação, FURG / CNPq. Contatos: R. Manoel Francisco Moita, 47 - Cassino - Rio Grande - RS. CEP: 96205430 ou clamosilta@yahoo.com.br

2 Mestre em Educação Ambiental, doutoranda em Educação FaE/ UFPEL, professora do Centro Federal de Educação Tecnológica de Pelotas, CEFET-RS e coordenadora do PhotoG raphein - Núcleo de Pesquisa em Fotografia e Educação, FURG / CNPq. attos@vetorial.net

3 D outora em Educação, professora Associada IE/ PPGEA/FURG, e pesquisadora do PhotoGraphein - Núcleo de Pesquisa em Fotografia e Educação, FURG/ CNPq. elisabethschmidt@ furg.br 
thinking and acting, represents the possibility of resignifying and renewing human thought/ knowledge. Aesthetics is an essential element that allows the sensitive comprehension of cultural and social factors and the appearance of different mentalities and behaviours. That understanding allows us to think the subject through smooth movements, like the poetic and political power of institutionalised elements, and therefore we can reflect on the relations between ethics and aesthetics, politics and art, in contemporary society.

Keywords: Aesthetics; Environmental Education; Complexity.

As artes levam-nos à dimensão estética da existência e - conforme 0 adágio que diz que a natureza imita a obra de arte - elas nos ensinam a ver 0 mundo esteticamente. Trata-se, enfim, de demonstrar que, em toda grande obra, de literatura, de cinema, de poesia, de música, de pintura, de escultura, há um pensamento profundo sobre a condição humana. (EDGAR MORIN)

\section{Primeiras Aproximaç̧̃es}

O autor da epistemologia da complexidade, o sociólogo francês Edgar Morin, ao perder sua mãe, antes mesmo de completar dez anos de idade, foi precocemente iniciado na compreensão do significado de contradições existenciais, tais como vida e morte, alegria e tristeza. Essa dialógica vivencial posteriormente se transformou em fonte de reflexão, constituindo-se numa das bases antropológicas do pensamento complexo (MORIN, 1997), uma forma de/do pensar que possibilita a compreensão da realidade, dos processos vitais e culturais, em suas dimensões específicas, como constituintes de elementos ao mesmo tempo antagônicos, complementares e concorrentes entre si.

O paradigma dominante, herdado da ciência moderna, é intitulado por Morin (2001) de "paradigma da simplificação", pois, ao focar o real com o predomínio da parte, fragmenta a noção do todo. O pondo-se a essa mentalidade linear e reducionista, Morin propõe um pensamento que integre os distintos modos de pensar, ou seja, que una os aspectos presentes no universo ao invés de separálos: 
um big bang, como quer Edgar Morin, caracteriza o novo perfil da ciência, sobretudo a partir da segunda metade do século vinte. Isso é compreensível: ao panorama de uma sociedade-mundo que tem que se haver com uma multiplicidade de fenômenos e problemas de toda ordem e em todo lugar, corresponde uma explosão descontrolada de engenhos científicos (ALMEIDA, 2004, p. 15).

Com o objetivo de unificar e homogeneizar os procedimentos e critérios comportamentais, as sociedades, em suas diversidades, ditam regras que são incorporadas pelos grupos. O sujeito faz parte da comunidade, e essa faz parte dele por meio de suas normas, linguagens e culturas, agindo, ao mesmo tempo, como produtos e produtores da sociedade. Esse é um dos princípios da epistemologia da complexidade, no qual se entende que a parte está no todo, assim como o todo está na parte, sendo que cada parte, embora conserve suas características próprias, contém a totalidade do real. Eis o que Morin chama de uno múltiplo (MORIN, 2002), ou seja, a diversidade registrando-se numa unidade da vida, na qual as regras sociais não somente distinguem os povos como aproximam os sujeitos membros de um grupo. Nesse contexto, deparamo-nos também com a grande dificuldade em conceber a unidade do múltiplo e a multiplicidade do uno:

o paradoxo da unidade múltipla está em que o que une separa (...). Aquilo que permitiria a compreensão provoca a incompreensão entre culturas, quando se vê apenas a diferença e não 0 fundo antropológico comum (MORIN, 2002, p. 65).

Morin apresenta-nos o termo complexidade não apenas como um conceito, mas como uma forma de enxegamms a realidade, ou seja, indica a compreensão dos desafios que nos são colocados cotidianamente, já que a visão que temos da realidade é sempre parcial, incompleta. Desde há muito aprendemos e ensinamos separando as partes do todo, a razão da sensibilidade, um modelo epistemológico que ainda persiste e que para 0 autor impede 0 entendimento do que chamamos realidade. 


\section{Complexidade e educação ambiental}

Quando se fala de complexidade, o termo diversidade emerge naturalmente. Aceitar a condição de ser/ estar num mundo complexo implica ultrapassarmos as barreiras sociais que muitas vezes impedem a aceitação das diferenças inerentes à condição da multiplicidade de formas e vidas que povoam o planeta. É nesse contexto, múltiplo e diverso, que o paradigma da complexidade interage com a perspectiva da Educação Ambiental (EA), na busca por um entendimento mais sensível e amplo das relações ambientais, propiciando assim a superação da cosmovisão antropocêntrica e a necessária transformação nos pensamentos e ações, como destaca a pesquisadora Michèle Sato (2002, p. 2):

na tessitura desta diversidade, cremos que o maior desafio da EA se ajusta na busca da alteridade - no respeito aos diferentes. É preciso desejar a transformação social através da participação de idéias plurais contidas na essência reflexiva para uma Terra com mais responsabilidade ecológica. Se for realmente verdade que desejamos um mundo melhor, com desejos arrepiando peles, gestos, falas e atitudes despertando paixões e até permitir deixar arriscar os fôlegos suspensos, também é igualmente verdade que em nós repousa 0 maior trabalho. Somos nós que temos a árdua tarefa de realizar, inescrupulosamente, nossos sonhos e fantasias.

A explicação de Layrargues (2004), na apresentação do livro Idantidades da EduraçãoAmbiental Brasilera, organizado pelo Ministério do Meio Ambiente (MMA), é de significativa ajuda no entendimento das interconexões da EA com os demais aspectos da vida. O autor argumenta que a expressão "educação ambiental" tem uma essência, que é constituída pelo substantivo edraçãa tendo 0 adjetivo ambietal a função de anunciar o contexto dessa prática educativa, princípio que motiva a ação pedagógica.

É possível optarmos pelo entendimento de que 0 que nos rodeia não está relacionado com o que somos. Esse pensar encaminhanos para atitudes que podem ser de total desprendimento, sem qualquer 
reflexão a respeito do nosso agir cotidiano. Essa concepção repercute profundamente no modo como enxergamos a Vida e, consequentemente, no caminho do fazer educativo para nela e com ela habitar.

Para a construção dos conceitos de EA, é preciso estar familiarizado com uma gama de outros conceitos, tais como: ambiente, natureza, sustentabilidade, que, por sua vez, influenciam a perspectiva ambiental da educação. É preciso considerar a EA em sua extensão elementar e complexa. Não há como situá-la apenas por um viés social ou natural - pois são duas dimensões interligadas, que se complementam, oferecendo uma magnitude de difícil conceituação rápida. Dependendo das concepções, o cenário educativo passa a contemplar o ambiental como uma parte constitutiva do ser humano ou não.

0 ambiente deve ser compreendido com mais amplitude, como atmosfera que circunda a vida do homem, assim como as demais vidas no seu entorno, como extensão do individual, do social, do ecológico, do cultural e do afetivo. No entanto, essa atmosfera sofre modificações através dos tempos e, sendo essas positivas ou não, uma postura educacional se faz necessária, com 0 intuito de problematizar e refletir sobre a situação ambiental em sua complexidade.

D eparamo-nos ainda com atividades ditas como de EA que, no entanto, carregam inerentes aos seus discursos, no conteúdo desenvolvido ou mesmo na metodologia de trabalho aplicada, as concepções antropocêntricas que sustentam a visão da superioridade do ser humano ante a Natureza, muitas vezes apresentando uma perspectiva conservadora. A razão disso, segundo Guimarães (2004), é que essas práticas estão presas a uma amadilha paradignática, ou seja, inconscientemente uma visão preponderante de mundo controla os modos de pensar e agir da sociedade, visíveis através dos próprios movimentos dominantes nela revelados.

A relação sociedade-natureza, pelo viés tradicional da educação vinculada ao pensamento cartesiano da Modernidade, que busca a estabilização do mundo exterior através da sistematização racionalista, se estabelece através de olhares que negam a compreensão sensível do 
mundo. A visão utilitarista e a ética antropocêntrica reforçam a ideia de que o mundo foi criado para o deleite dos seres humanos.

Assim, acreditamos que uma das tarefas mais instigantes da EA e de todos os processos educativos na atualidade é a de redirecionar 0 indivíduo para a sua inerente capacidade criativa e dialógica, afastando0 de uma percepção de mundo puramente racional. Naquele entendimento, o ser humano, ao ter estruturado o mundo de forma tão rígida e homogênea, acabou por afastar-se desse devido à falta de reconhecimento, ao estranhamento que o mesmo veio a provocar-lhe. No contexto desta reflexão é que percebemos a necessidade de 0 sujeito reencontrar a si mesmo a fim de encontrar-se com o mundo. Sem o conhecimento de sua natureza criadora, afetiva, simbólica, instintiva, 0 ser humano torna-se impossibilitado de entender 0 movimento do mundo do qual deveria sentir-se parte integrante.

$\mathrm{Na}$ compreensão de que somos constituídos por uma pluralidade de aspectos, sejam eles sensíveis, racionais, complexos, morais, afetivos, culturais, nos apoiamos na concepção de Maffesoli da vida como algo multirreferencial, essa ética da estética, que para o autor trata-se do "laço social baseado em emoções comuns, sentimentos compartilhados, afetos postos em jogo na cena pública" (MAFFE SOLI, 2003, p. 68), como suporte para diversas formas de sociabilidade que enfatiza o sensível. 0 autor refere-se ao estético como uma forma de ser que prepondera nas sociedades, de experimentar e sentir com os Outros, sem a submissão aos juízos de gosto. A estética assim entendida se estende enquanto processo de equivalência ao ambiente, seja natural, cultural ou social; "não é somente a perfumaria da linguagem técnica rara, é a linguagem do dia-a-dia, tecendo o gosto do prazer/ desprazer sobre o cotidiano. Marca o expresso e 0 não dito, 0 público e o íntimo, como se fora um currículo, às vezes, explícito, outras, oculto" (SATO, 2002, p. 7).

Entendemos ser primordial, frente à dimensão educacional estabelecida, dialogarmos sobre os "valores éticos"4 que, por sua vez,

4 O conceito de valures étices utilizado na presente reflexão tem como base 0 entendimento de Nicola Abbagnano (2000), que considera a Ética como a ciência 
implicam os estéticos, na forma como nos relacionamos com o mundo através dos sentidos, antes mesmo de qualquer ação educativa. Os valores ético-estéticos colaboram para o desvelamento de posturas submissas, reprodutoras de discursos/ fazeres sem uma observação mais apurada, sem uma reflexão crítica que favoreça mudanças na formação dos sujeitos contemporâneos. Tais valores podem ser construídos a partir de um olhar mais justo para com as relações socioculturais, favorecendo outras posturas frente ao meio ambiente.

É possível sim definir maldade, bondade, egoísmo, entre outros juízos de valores, já que essa é uma condição ética, mas como fatos da vida humana que se caracterizam em determinadas circunstâncias e que resultam de processos pessoais e psicológicos associados às dimensões externas familiares, comunitárias, de classe etc. Cabe a nós descobrirmos as razões que levam a identificarmos comportamentos como estando inseridos dentro de um desses valores e suas condicionantes, e estabelecer o movimento de superação daqueles valores, atitudes e comportamentos que julgamos como impróprios à vida social (LOUREIRO, 2004, p. 129).

Cresce a cada dia o número de teóricos que defendem a necessidade de investirmos na reconstrução das próprias referências culturais (imagens em todos os seus sentidos e formas que subjetivamente nos conduzem no dia a dia) como forma de (re)estabelecermos o ciclo da vida no planeta). Maffesoli (2003), Szaniecki (2007) e Hernández (2007) revelam a preocupação com as relações estéticas no cotidiano das vivências como reflexos dos valores sociais orientadores das mentalidades e posturas de cada sujeito e viceversa.

Sabemos 0 quanto 0 modelo econômico vigente afeta diretamente a maneira como os sujeitos lidam com a realidade, com 0 cotidiano da vida e das relações interpessoais e, mais especificamente,

do mód da conduta humana, apontando seus "motivos" ou "causas", ou as "forças" que a determinam, pretendendo ater-se ao conhecimento dos fatos. 
com as relações frente ao meio natural. Hábitos são incorporados e naturalizados. Assim como as árvores são constantemente enfeitadas com as sobras e os excessos de sociedades cada vez mais consumistas (Foto 1), desconsideradas e desrespeitadas por relações objetais instituídas, ignoramos frequentemente a teia da vida (FRITJOF, 2001).

Foto 1 - Sem título, 2008. Local: Praia do Cassino. Fonte: Claudia Tavares

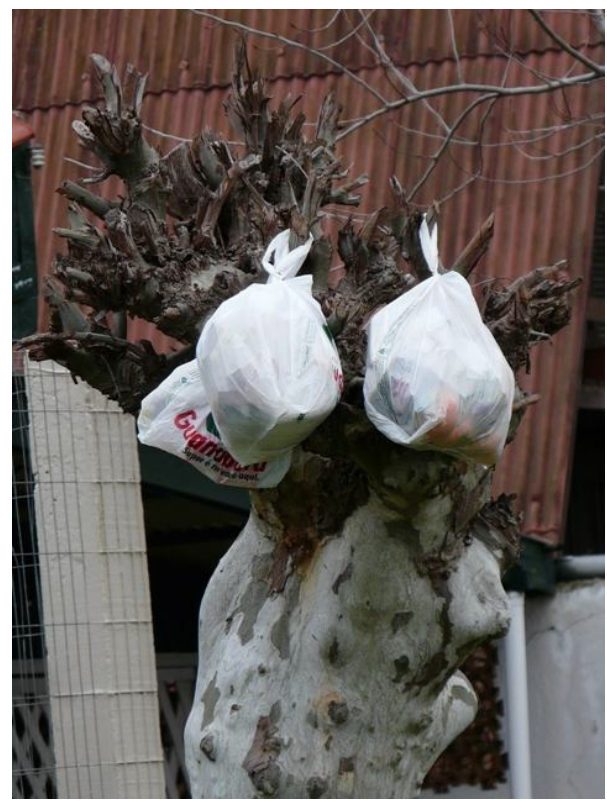

As imagens se apresentam como algo que precisa ser entendido: 0 ver, na contemporaneidade, foi superado pelo perceded interprear/ compreender. Trata-se do "alfabetismo visual", como defende Hernández (2007, p. 29), no entendimento de que somos influenciados muito mais pelo mundo imagético que nos rodeia, pelas subjetividades despertas e também pelas possibilidades de interlocução do conhecimento do que pelas leituras ou pelo que ouvimos. É de extrema relevância discutir sobre as representações visuais individuais e coletivas, levando em consideração a produção de subjetividades pelo viés "controlador" de gerações consumistas e egocêntricas, que se encontram interligadas às demais práticas culturais de socialização. E ainda, as representações 
visuais, quando (res)significadas, nos ensinam o dhar para si - numa construção/ transformação de representações de si e sobre o mundo.

É visível que a EA não encontra possibilidades de desenvolvimento na perspectiva da ética antropocêntrica. Para rompermos com a visão utilitarista, necessitamos de ideias e atitudes em prol de valores que estimulam o surgimento de novas sensibilidades e possibilitam outras racionalidades complementares. Entendemos que a postura ética de responsabilidade com as ações exercidas no/ para 0 presente e futuro decorre de uma percepção estética ao entender 0 O utro ${ }^{5}$ como parte de nós, numa relação de alteridade existencial, assim como de cuidado, sob a compreensão do sentido ético-estético necessário às práticas diárias individuais e coletivas. 0 Outro diz respeito ao que está fora e dentro de nós ao mesmo tempo, e não somente à percepção deste. Ao compreendermos as inter-relações do ser humano com o meio cultural, social e natural, por esse prisma, percebemos as interdependências existentes desses aspectos com a nossa corresponsabilidade nas realidades socioambientais.

$\mathrm{Na}$ ânsia por uma EA que perceba o ambiente como um reflexo da ação humana, ressaltamos a importância da compreensão sobre a complexidade ambiental resultante de interações de seus aspectos complementares - biológicos, sociais, físicos, econômicos e culturais que produza uma interpretação de coexistência e corresponsabilidade para uma futura e prudente utilização dos recursos naturais, assim como para as inter-relações humanas. Tal compreensão pode também favorecer a percepção da relação e da relevância do meio ambiente nas atividades econômicas, educacionais, sociais e culturais, clarificando 0 direito e o dever da participação de todos no momento de conceber e aplicar decisões.

Examinamos ponderadamente que a EA deve desenvolver a competência de auxiliar o sujeito na percepção do espaço onde ele vive, do Outro pelo qual é constituído. Acreditamos que a relação do ser

5 A expressão Outro refere-se à reflexão e conduta ético-existenciais sobre 0 reconhecimento e acolhimento da alteidadeabsoluta do outro, seja ele de natureza humana ou não, apoiados no pensamento de Lévinas (2005). 
humano com o meio deve ser conquistada através da sensibilidade, da percepção e da reflexão crítica. Entretanto, é importante salientar a existência de uma visão equivocada sobre "sensibilização", muitas vezes adotada nas práticas da EA, assim como aquela implícita em "ações pontuais de abraçar árvores ou oficinas de reciclagem de papel, sem nenhuma postura crítica dos modelos de consumo vivenciados pelas sociedades, ou pela análise do modo de relação dominadora do ser humano sobre a natureza, com alto valor antropocêntrico" (SATO, 2001, p. 3). Torna-se necessário o exercício da sensibilidade com base em um processo educativo que possibilite, através da valorização, do reconhecimento, da ação/transformação e da responsabilidade, uma relação ética e estética, de ordem sustentável e consciente, do sujeito com o meio.

\section{Manifestações da estética num mundo complexo}

Refazer e recriar os sentidos é um ofício constante de quem desvenda a trama, puxando fios soltos que saíram da meada, incluindo outros que não form bordados outrora tecidos por outras mãos. (MICHĖLE SATO)

Ao longo dos séculos, o afastamento entre o homem e a natureza deixou suas marcas nas relações entre o ser humano e o meio ambiente. Ainda hoje, nos tempos da Pós-Modernidade, esse olhar encontra-se projetado em formas estereotipadas de ver o mundo, como, por exemplo, não enxergar a rua da própria casa como uma extensão do pátio, e de nós mesmos, e, dessa forma, relegar toda uma dimensão espacial que, de fato, relaciona-se diretamente com a nossa vida, mas que não é compreendida como tal. Esse olhar estereotipado atinge em grande escala as situações vigentes de calamidade social; trata-se de uma falta de pertencimento ao planeta Terra, sustentada pelo pensamento dicotômico de homem x natureza. Relacionamos rapidamente essa herança cartesiana/ objetiva com a própria perspectiva surgida na Renascença, cujos princípios almejavam 0 aprisionamento do real, 
afirmando uma única forma de representação, com base no emprego de cálculos matemáticos rigorosos para as proporções, tanto das figuras humanas como das construções arquitetônicas. Tal projeto de perspectiva tornou-se superior, em termos do poder que representava na época, ao próprio dhar humano que enxerga a realidade pelo viés de seus sentidos, que busca ver o mundo em sua completude, com suas relações e inter-relações, cheio de imperfeições e outras características particulares do movimento da Vida.

Atualmente, com a infinidade de imagens que pontuam nosso cotidiano, faz-se necessário um reaprender a dhar que possibilite ver 0 mundo de forma a admirar-se, a espantar-se, enfim, de forma a percebê-lo de modo sensível. Falamos de um olhar atento no sentido cuidadoso da palavra, com sentimentos voltados para o inisíved por detrás da visibilidade ofuscante que se apresenta a nós.

0 campo perceptivo do dhar nos afortuna com sua essência investigativa quando, sensível e crítico, nos proporciona o espanto da descoberta de outro mundo circundante, camuflado muitas vezes sob o benefício de olhares cansados e reprodutores de visões calcadas em "verdades absolutas". Compreendemos então que não basta olhar; é preciso dhar com cautda, com paciência e vontade de desenvolver sensações visuais únicas - um olhar que amplie as possibilidades de significados.

A questão do dhar formatado pode ser ilustrada com o "Mito da Caverna", de Platão (Livro VII de A República, 380-370 a.C.), uma metáfora da condição humana que, de acordo com o filme Janda da Alma(2001), permanece atual:

O que eu acho é que nós nunca vivemos tanto na caverna de Platão como hoje. Hoje é que estamos a viver, de fato, na cavema de Platão. Porque as próprias imagens que nos mostram a realidade estão expostas de uma maneira que substituem a realidade. Nós estamos num mundo que chamamos mundo audiovisual. Estamos, efetivamente, a repetir a situação das pessoas aprisionadas ou atadas à caverna de Platão: olhando em frente, vendo sombras e acreditando que essas sombras são a realidade. Foi preciso passarem todos esses 
séculos para que a caverna de Platão aparecesse, finalmente, num momento da história da humanidade, que é hoje. E vai ser cada vez mais.

No "Mito da Caverna”, Platão descreve a condição de pessoas aprisionadas numa caverna e que, acorrentadas, são obrigadas a olhar sempre para a mesma parede. A única "realidade" que vislumbram são frutos da penumbra, de sombras projetadas pela pouca iluminação que penetra através da entrada, como uma simulação da realidade que se torna a própria realidade. Se nessa situação, continua Platão, uma pessoa conseguisse libertar-se e fugir, inicialmente sofreria pela forte luz natural em seus olhos; por outro lado, logo se maravilharia com a quantidade de novas formas, novos objetos e pessoas que se apresentariam, libertando-se assim do aprisionamento dbdhar, da visão das sombras. No entanto, se o fugitivo voltasse para relatar o que viu, ninguém lhe daria crédito: ele seria rechaçado por todos. Podemos, portanto, relacionar a questão fundamental do dhar fomatado da narrativa platônica, assim como a condição de submissão de quem está dentro da caverna, com a negação de outras possibilidades de existência da própria realidade.

Vivemos em um mundo onde as nossas necessidades ultrapassam os limites possíveis, tencionando a natureza de forma a levá-la ao seu limiar, submetendo-a a abusos traumatizantes e transformando-a de maneira irreversível. Infelizmente, se não observarmos os acontecimentos ao nosso redor, por mais simples que eles sejam, estaremos abdicando de desvendar, conhecer e compartilhar tudo aquilo que prodigamente Gaia nos oferece. Tal oferenda é generosa, mas, se não for respeitada em seus atributos, sucumbirá, levando consigo a vida em toda a sua multiplicidade.

(Res)significando 0 ambiente, ou melhor, a visão sobre 0 mesmo, numa perspectiva cuidadosa com o Outro - seja ele humano ou natural -, direcionamos as práticas em EA para a reorientação dos valores ético-estéticos. São valores que implicam os modos de percepção e de recepção da realidade incorporados ao processo 
histórico/ atual, muitas vezes sem uma postura reflexiva a respeito, isto é, adotando maneiras de viver individual e coletivamente padronizadas.

Não somos totalmente passivos no processo de construção de valores: somos cooperadores na reprodução dos mesmos, levando em conta o sujeito e seus contextos sociais, culturais e econômicos. Novos valores e significados não devem centrar-se apenas no indivíduo ou no coletivo; devem ser contextualizados histórica e socialmente na relação com ambos, a fim de uma melhor percepção e intervenção da realidade.

Embora mudanças estejam em andamento, estamos, nós educadores, muitas vezes aprisionados à tradição educacional fundamentada na transmissão de informações, à "educação bancária", como diria Paulo Freire.

A emergência do paradigma da educação como exercício da comunicação, da troca dialógica, pressupõe a formação crítica voltada para a emancipação do ser humano. Esse desafio soma-se à necessidade de atrelarmos às práticas educativas a reflexão a respeito das interligações da estética com a constituição ética dos sujeitos. As relações entre as nossas sensibilidades estéticas e as éticas indicam a necessidade de trilharmos 0 caminho da produção de subjetividades para a mudança de comportamentos e atitudes. Subjetividades essas que não privilegiem a fragmentação racional, a linearidade e a ordem em detrimento da complexidade, da criatividade e do imaginário da vida.

A apropriação dos dispositivos presentes no modelo econômico vigente, que Szaniecki (2007) denomina formas de trabalho do capitalismo cogitivo é fundamental para a criação de linguagens que comuniquem a crítica aos mecanismos/ instituições de poder existentes em tal modelo e, consequentemente, para o processo de renovação e transformação do mesmo.

Através das manifestações, das "potências estéticas" ${ }^{6}$, sabemos que se faz possível o questionamento de diferentes perspectivas,

6 Quanto à produção e à expressão estética presentes na contemporaneidade, Szaniecki (2007, p. 98) defende que o que se entende por estética de potência é uma "criação que não se limita à representação crítica do poder, mas constitui novas linguagens através do trabalho da multidão". 
movimentos, enfim, até do papel do próprio saber, no que se refere à sua capacidade para o poder, para o controle. Uma ilustração para esse pensamento são os movimentos de maio de 1968, tanto no Brasil como na Europa, que geraram importantes questionamentos "sobre as instituições de ensino, sobre o papel do estudante na sociedade" (SZANIECKI, 2007, p. 89). Nessa perspectiva, presenciamos a força, 0 potencial estético de algumas produções sem pretensões artísticas, ou seja, produções que não se identificam com a instituição museu, sendo sua preocupação maior a potência em suas expressões, visando à transformação dos olhares e pensamentos acatados perante 0 autoritarismo político, social e cultural, muitas vezes camuflado de democrático.

$\mathrm{Na}$ fotografia abaixo reproduzida, podemos detectar sentidos de reflexão sobre as condições humanas e as relações ambientais atuais. Tais "aparições" ficam muitas vezes "esquecidas" frente aos olhares anestesiados pelo excesso de imagens que compõem os cenários das cidades contemporâneas. O dhar sensive é fundamental para a percepção de manifestações visuais potencialmente estéticas como essa (foto 2), permitindo o contínuo despertar de uma percepção ambiental crítica, humanizada e justa.

Foto 2 - Sem título, 2008. Prédio da Faculdade de Educação da UFRG S, Porto Alegre. Fonte: Claudia Tavares

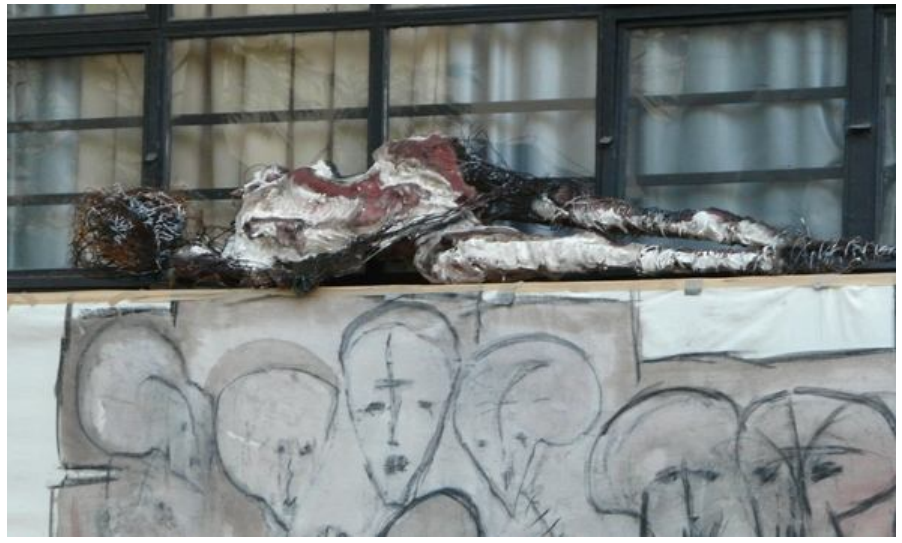


O que se pretende expressar, com este exemplo, é que posturas reflexivas e críticas das relações estabelecidas na sociedade, nas esferas culturais, econômicas, familiares e históricas, podem ter seu princípio, entre outras formas, através das manifestações/ expressões estéticas que nos rodeiam, diretamente relacionadas às produções de subjetividades, guia de visões e entendimentos que, por sua vez, direcionam atitudes e mentalidades.

\section{Tecendo considerações finais}

Falar sobre Estética torna-se imprescindível àqueles que almejam (res)significar o mundo, pois ela permite que o ser humano desenvolva uma nova percepção do todo à sua volta. Nas sociedades multiculturais contemporâneas, buscam-se aproximações e convergências - já que as diferenças são facilmente identificadas! - , sendo a Estética uma possibilidade para a elaboração de diálogos comuns. Partindo da subjetividade dos indivíduos e de suas representações sociais, as experiências sensíveis facilitam a (auto)compreensão através do confronto entre as diferenças vivenciadas na relação com o O utro e consigo mesmo, dando início ao processo de tomada de consciência do ser/ estar no mundo.

Sem conhecer a si próprio, o ser humano age mecanicamente, negando sua individualidade e também 0 coletivo - 0 Outro -, conduzindo-se, por fim, a um estado de tamanha apatia que compromete o significado da própria existência humana. Isso leva à falência de todas as possibilidades de recriação, crescimento, liberdade e espontaneidade. É partindo dessa visão que defendemos a necessidade de que o sujeito veja a si mesmo como agente ativo e transformador da sua própria condição de vida.

Acreditamos que o processo educativo deva contemplar 0 sujeito em sua complexidade, enfatizando o aprendizado através de suas vivências por meio dos sentidos e das percepções do próprio corpo. Q uando ao indivíduo é possibilitada uma interação ampla/ aberta com as questões que devem ser apreendidas, não se está apenas projetando uma determinada realidade, fruto de um contato parcial de vivências, 
está-se produzindo conhecimento, pois o sujeito estará atento às suas percepções, sensível aos sinais de seu próprio corpo em interação com os ambientes externos, assim como com suas ideias e imagens internas.

A EA, ao aspirar a uma compreensão dos sujeitos sobre as questões de ação responsáve no mundo, sobre 0 fato de que a participação humana encontra-se num contexto que interliga o passado, 0 presente e o futuro, busca 0 vivencial como tendência pedagógica em suas ações/ intervenções. Entre seus compromissos, está a atenção às necessidades da natureza humana, estimulando sensibilidades, afetividades, capacidades de imaginação e de criação, possibilitando, assim, o despertar para a essência ética do ser humano. 0 viés da Estética, a eduraçãodb sensived, vai ao encontro dessas necessidades como um recurso simbólico que se constitui numa ferramenta de extrema importância para os processos educativos.

Em hipótese alguma pretendemos esgotar o assunto com este texto. A proposta é fomentar uma discussão/ reflexão sobre as inúmeras instâncias orientadoras de valores ético-estéticos e de práticas educativas voltadas para uma perspectiva ambiental coerente com as condições da realidade vigente. A Educação Ambiental, mais do que uma nova forma de pensar ou agir, representa uma possibilidade de renovação do próprio pensamento/ conhecimento humano. Nesse sentido, seu maior objetivo é o de preparar os indivíduos, por meio da sensibilização, informação, contextualização e ação reflexiva/ crítica, para a compreensão dos principais problemas do mundo contemporâneo. A EA, desenvolvida dessa forma, contribui para a qualificação ética e estética dos sujeitos, capacitando-os para atuações sociais responsáveis, coerentes com a perspectiva de melhorar a vida em sua amplitude. 0 que defendemos é a necessidade de uma educação conectada com os sentidos, com as concepções individuais e coletivas vivenciadas, possibilitando, assim, a transformação de comportamentos, o desenvolvimento de novos olhares, de novas maneiras de viver e de criar a própria condição de vida. 


\section{Referências}

ALMEID A, Maria da Conceição de. Mapa inacabado da complexidade. In: SILVA, Aldo Aloísio Dantas da; GALEANO, Alex (Org.). Geografia: ciência do complexus: ensaios transdisciplinares. Porto Alegre: Sulina, 2004. p. 9-41.

BACHELARD, Gastón. A dhama deuma vda Tradução de Glória de Carvalho Lins. Rio de Janeiro: Bertrand Brasil, 1989.

CAPRA, Fritjof. A teia da vida: uma nova compreensão científica dos sistemas vivos. Tradução de Newton Roberval Eichemberg. 6. ed. São Paulo:Pensamento; Cultrix, 2001.

GUIMARÃES, Mauro. A fommããodeeduradoresambientais São Paulo: Papirus, 2004.

HERNÁNDEZ, Fernando. Catadores da altura visual: transformando fragmentos em nova narrativa educacional. Tradução de Ana Duarte. Revisão técnica de Jussara Hoffmann e Susana Rangel Vieira da Cunha. Porto Alegre: Mediação, 2007.

JANELA DA ALMA. Direção: João Jardim, Walter Carvalho. São Paulo: BR distribuidora; Brasil Telecom; Ravina filmes. 2001. Filme, 73 min. Color Son. DVD.

LO URE IRO, Carlos Frederico B. Trajєónia e fundametos da eduraşão ambiental. São Paulo: Cortez, 2004.

MAFFESOLI, Michel. O instante tema 0 retomo do trágico nas sociedades pósmodernas. Tradução de Rogério de Almeida e Alexandre Dias. São Paulo: Zouk, 2003.

MO RIN, Edgar. Meus Dêmâios Tradução de Leneide Duarte e Clarisse Meireles. Rio de Janeiro: Bertrand Brasil, 1997.

. Introuruãa ao pensametocomplexa. 3. ed. Lisboa: Stória, 2001.

. O mútobb 5: a humanidade da humanidade. Tradução de Juremir Machado da Silva. Porto Alegre: Sulina, 2002.

PLATÃO . A república Brasília: Editora da Universidade de Brasília, 1985.

SATO, Michèle. Debatendb desafios da eduração ambietal. In: CONGRESSO DE EDUCAÇÃO AMBIENTAL PRÓ-MAR DE DENTRO, 1., 2001. Rio Grande. Anais.. Rio G rande, 2001, p. 14-33.

SATO, Michèle; PASSO S, Luiz A. Vessos erearsos da diversidade In: SIMPÓ SIO SULBRASILEIRO DE EDUCAÇÃO AMBIENTAL, 1.; SIMPÓSIO GAÚCHO DE EDUCAÇÃO AMBIENTAL, 2., 2002. Erechim. Anais.. Erechim: URI, 2002, p. 115126. (Conferência de abertura). Disponível em: <http:/ / www.ufmt.br/ gpea/ pub/ Erechim_diversid.pdf> . A cesso em: 03 abr. 2007.

SZANIECK I, Barbara. Estática da milticăa Rio de Janeiro: Civilização Brasileira, 2007.

WEIL, Pierre. Organizaçós e teendogas para o tecciro milênio - nova cultura organizacional holística. Rio de Janeiro: Rosa dos Tempos, 1991.

Artigo: recebido em 06/ 07/ 2009 - aprovado em 05/ 09/ 2009. 